$\mathrm{P}_{2} \mathrm{O}_{5} \mathrm{SBF}$ paper; MDO

\title{
THE EFFECT OF PHOSPHATE CONTENT ON THE BIOACTIVITY OF SODA-LIME- PHOSPHOSILICATE GLASSES
}

\author{
M. D. O’Donnell ${ }^{1,2 *}$, S. J. Watts ${ }^{1}$, R. G. Hill ${ }^{1}$, R. V. Law ${ }^{2}$ \\ ${ }^{1}$ Department of Materials, Imperial College London, UK \\ ${ }^{2}$ Department of Chemistry, Imperial College London, UK
}

\begin{abstract}
We report on the bioactivity of two series of glasses in the $\mathrm{SiO}_{2}-\mathrm{Na} a_{2} \mathrm{O}-\mathrm{CaO}-\mathrm{P}_{2} \mathrm{O}_{5}$ system after immersion in simulated body fluid $(\mathrm{SBF})$ after 21 days. The effect of $\mathrm{P}_{2} \mathrm{O}_{5}$ content was examined for compositions containing 0 to 9.25 mol. \% phosphate. Both series of glasses degraded to basic pH, but the solutions tended towards to neutrality with increasing phosphate content; a result of the acidic phosphate buffering the effect of the alkali metal and alkaline earth ions on degradation. Bioactivity was assessed by the appearance of features in the X-ray diffraction (XRD) traces and Fourier transform infrared (FTIR) spectra consistent with crystalline hydroxyl-carbonate-apatite (HCAp): such as the appearance of the (002) Bragg reflection in XRD and splitting of the P-O stetching vibration around $550 \mathrm{~cm}^{-1}$ in the FTIR respectively. All glasses formed HCAp in SBF over the time periods studied and the time for formation of this crystalline phase occurred more rapidly in both series as the phosphate contents were increased. For $\mathrm{P}_{2} \mathrm{O}_{5}$ content > 3 mol. \% both series exhibited highly crystalline apatite by 16 hours immersion in SBF. This indicates that in the compositions studied, phosphate content is more important for bioactivity than network connectivity $(N C)$ of the silicate phase and
\end{abstract}

\footnotetext{
* Author is currently at BioCeramic Therapeutics Ltd, London, UK.
} 
compositions showing rapid apatite formation are presented, superior to 45S5 Bioglass ${ }^{\circledR}$ which was tested under identical conditions for comparison.

\section{Introduction}

Bioactive glasses and ceramics have been important for mineralised tissue regeneration in orthopaedic applications for over 30 years [1]. However, recently these materials are finding usage in products such as toothpaste as reminerialising agents [2]. The toothpaste Sensishield marketed in the EU by Periproducts contains Novamin (45S5 Bioglass $®$ ) as the active ingredient and there is also a toothpaste on the market which contains a zinc substituted hydroxyapatite [3]. L'Oreal also have a patent [4] for Bioglass as an additive to products for relaxing / straightening hair. This opens up the possibility for bioactive glasses to be used in a variety of consumer products.

This study reports the bioactivity of two series of glasses of which structure and properties have been previously reported $[5,6]$. In series I phosphate was added to the glass, replacing $\mathrm{SiO}_{2}$ and the $\mathrm{Ca}$ to $\mathrm{Na}$ ratio was kept constant. In series II, it was assumed phosphate did not enter the silicate network, but formed a separate orthophosphate phase and sufficient $\mathrm{Ca}$ and $\mathrm{Na}$ was added to ensure charge neutrality in the $\mathrm{PO}_{4}{ }^{3-}$ complex formed. As the previous study showed, the formation of this type of phosphate structure resulted in removal of network modifiers in series I, polymerising the silicate network and resulting in an increase in $\mathrm{Q}^{3}$ structural units and a reduction in $\mathrm{Q}^{2}$. In series II, as sufficient modifier was added to charge balance the orthophosphate species, no change in the silicate structure was seen by solid state NMR; effectively the silicate network remained $\mathrm{Q}^{2},\left[\mathrm{Si}_{\mathrm{n}} \mathrm{O}_{3 \mathrm{n}}\right]^{2 \mathrm{n}-}$ chains of infinite molar mass.

Simulated body fluid (SBF) has been used in vitro in a large number of studies to predict in vivo bioactivity in particular in glass-ceramic systems to assess the formation of hydroxyl-carbonated-apatite at the surface of the material (HCAp). The formation of HCAp after a reasonable time period in SBF is a good indicator that the material will form a bond and integrate well with bone in vivo. Although SBF experiments should be complemented by cell studies, followed by animal and human trials, SBF data can be used to screen out materials for these expensive and possibly unnecessary studies. The 
glasses studied here are modifications of the original 45S5 Bioglass $®$ composition [1] and glasses studied by Elgayar et al. [7], with phosphate added to investigate the effect on bioactivity. The two most obvious negative effects in vivo might be degradation of the phosphate component of the glass producing an excessively acidic $\mathrm{pH}$ and hence cytotoxicity and pyrophosphate $\left(\mathrm{Q}^{1}\right.$ phosphate) species producing wide macrophagic activation [8]. It is know that all the glasses in this study contain a separate orthophosphate $\left(\mathrm{Q}^{0}\right.$ phosphate) phase. In the compositions studied the degradation and production of acidic $\mathrm{pH}$ caused by phosphate would be buffered by the large amount of basic ions $(\mathrm{Na}$ and $\mathrm{Ca}$ ) in the glass and should not result in an acidic $\mathrm{pH}$ as seen in polyphosphate glasses [9]. Acidic $\mathrm{pH}$ conditions is not desirable for the formation of crystalline apatite. We would not expect the production of pyrophosphate species either as all but one of the glasses studied have a network connectivity (NC) less than 2.5. Typically soda-lime-phosphosilicate glasses with NC $>2.5$ contain some phosphate in a $\mathrm{Q}^{1}$ configuration $[7,10]$.

\section{Experimental}

The processing of these glasses have been previously reported [5, 6]. Compositions can be found in table (1) also with network connectivity values assuming phosphate enters the glass network (NC) and that a separate orthophosphate phase is formed (NC').

$S B F$

Simulated body fluid was prepared according to Kokubo and Takadama [11]. Glass particles of diameter $<38 \mu \mathrm{m}$ were immersed in this solution in sealed containers for up to 21 days and were mechanically agitated at $60 \mathrm{rpm}$ using an incubator set to $37^{\circ} \mathrm{C}$. At various time points the samples were filtered and dried to constant weight for analysis by XRD and FTIR. 
A Phillips powder diffractometer with a copper $\left(\mathrm{Cu} \mathrm{K}_{\alpha}\right)$ X-ray source (Philips PW 1700 series diffractometer, Philips, Endhoven, NL) was used to characterise the glass samples. The powdered samples were recorded between 10 and $60^{\circ} 2 \theta$ at a scan speed of $0.04^{\circ} . \mathrm{s}^{-1}$. For crystallite size analysis high resolution scans of the (002) apatite peak were take between 24 and $28^{\circ} 2 \theta$ for a step size of 0.01 , collecting data on each step for $5 \mathrm{~s}$. Peak analysis was performed using SciDAVis 0.1 .3 software.

FTIR

FTIR spectra were obtained using a Bruker IFS 28 Fourier transform infrared spectrometer in the mid-IR range of 550 to $2000 \mathrm{~cm}^{-1}$ with a resolution of $0.2 \mathrm{~cm}^{-1}$. Powdered samples were pressed into pellets with $\mathrm{KBr}$. Peak analysis was performed using SciDAVis 0.1.3 software.

\section{Results and discussion}

$S B F$

Fig. (1) and (2) shows the variation in $\mathrm{pH}$ with time for series I and II glasses respectively after immersion in SBF. As a general trend the SBF becomes more basic with time. This is to be expected as more sodium and calcium ions are released. The solution also shifts towards acidity as the phosphate content of the glasses is increased in both series. This can be explained by the release of more phosphate from the glass which will buffer the alkalinity caused by the sodium and calcium ions. This decrease in $\mathrm{pH}$ is advantageous for bioactivity as a $\mathrm{pH}$ of 7.2 is optimal in physiological fluid for apatite deposition [8].

$X R D$

Fig. (3) and (4) shows XRD traces of selected glasses from series I and II. With progressing time we can see the formation of Bragg peaks associated with apatite crystallisation. The data is quite noisy and even after 21 days the apatite formed is 
relatively disordered. The most prominent features are the Bragg peaks at $25.9^{\circ}$ and $31.9^{\circ}$ corresponding to the (002) and (211) and reflections $[12,13]$. The region containing the (211) peak (30 to $35^{\circ}$ ) also contains a number of other features, namely the (112), (300) and (202) reflections $[12,13]$. However due to the noise and degree of peak overlap, these lines could not be used for crystallite size analysis. The (002) peak was used for this purpose. Apatite formation can be clearly seen after 16 hours. Fig. (5) shows the crystallite size obtained from the peak width and position of the 002 peak using the Scherrer equation [14]. After 21 days there is no real variation in the apatite crystallite size. For series II there is possibly a decrease in crystal size with phosphate content, but the variation over the series is less than the error of the peak fitting.

\section{FTIR}

Fig. (6) and (7) show FTIR spectra of selected glasses from both series immersed in SBF for up to 21 days. For the glasses containing phosphate, in the 500 to $600 \mathrm{~cm}^{-1}$ region there is a broad feature corresponding to the P-O bending mode and also a $\mathrm{Si}-\mathrm{O}-\mathrm{Si}$ bending vibration in this region $[13,15-17]$. Around $720 \mathrm{~cm}^{-1}$ in the glass spectra is the band due to $\mathrm{Si}-\mathrm{O}$ bending vibrations $[18,19]$. The dominant bands at approximately 910 and $990 \mathrm{~cm}^{-1}$ can be attributed to $\mathrm{Si}-\mathrm{O}\left(\mathrm{Q}^{2}\right)$ and $\mathrm{Si}-\mathrm{O}-\mathrm{Si}$ stretching vibrations respectively $[15,16]$. On exposure to SBF, vibrations from the silicate glass network decrease in intensity and bands due to the formation of crystalline hydroxyl-carbonate apatite become dominant. In particular the P-O bend and P-O stretch sharpen and increase intensity at around 580 and $1010 \mathrm{~cm}^{-1}$ respectively $[15,16]$. The P-O bend also shows the characteristic splitting indicative of crystalline apatite formation (into bands at 560 and $600 \mathrm{~cm}^{-1}$ ) [20]. The appearance of carbonate bands on exposure to SBF is also evidence of crystalline hydroxyl-carbonate-apatite formation with the $\mathrm{C}-\mathrm{O}$ stretch $\left(v_{2}\right)$ around 860 $\mathrm{cm}^{-1}$ and C-O asymmetric stretching $\left(v_{3}\right)$ at 1410 and $1450 \mathrm{~cm}^{-1}[16,21,22]$. The carbonate band at around $860 \mathrm{~cm}^{-1}$ can be seen to shift in position linearly (fig. (8)) to higher wavenumber for series I with increasing phosphate content in the original glass after 21 days exposure to SBF. It also increased for series II but levelled off in the high $\mathrm{P}_{2} \mathrm{O}_{5}$ samples (> 4 mol. \%). In the samples exposed to SBF the Si-O bending vibration 
reappears at higher wavenumber $\left(\approx 800 \mathrm{~cm}^{-1}\right)$ compared to the original glasses which indicates some degree of repolymerisation, possibly condensation of the silica gel formed in the SBF. Serra et al. saw this band shift to higher wavenumber with increasing silica, from 44 to 66 wt. $\%$, in bioactive glass samples [19]. The band seen around $1200 \mathrm{~cm}^{-1}$ in the 21 day SBF samples is due to a component of the asymmetric stretching mode of $\mathrm{Si}$ $\mathrm{O}[19,23,24]$.

\section{General comments}

All glasses showed formation of apatite in the 21day period tested in SBF. Table (2) summarises the time in which the characteristic splitting of the FTIR P-O bending mode at around $550 \mathrm{~cm}^{-1}$ was seen indicating crystalline apatite formation. As a general trend, apatite formation is faster as the phosphate content is increased in the parent glass; even in series $\mathrm{I}$ which shows an increase in network connectivity with increasing $\mathrm{P}_{2} \mathrm{O}_{5}$. This indicates that phosphate content is more important than network connectivity of the silicate phase for bioactivity in the range of compositions studied as long as the phosphate is present as $\mathrm{Q}^{0}$ species [5, 6]. The glass ICSW4, containing the highest phosphate content in both series does not fit in with the trend shown in table (2). It is know from previous studies that this sample was partially crystalline [5, 6] which would account for the slower rate of apatite formation compared to the other glasses.

The area of the P-O bending mode (also known as the $v_{4}$ phosphate region) can be seen to linearly correlate with the area of the (002) Bragg reflection from XRD as presented in fig. (9). The areas of these features after 21 days in SBF both increase with phosphate in the parent glass. This indicates that as a general trend, as more phosphate is added to the glasses, more apatite forms which suggests the phosphate content is more important in these two series of glasses than $\mathrm{NC}$ for mineralisation even though the network connectivity is increasing in series II and fixed in series II. Also as fig. (5) shows, the size of the apatite crystals are not varying with phosphate content in the parent glass after 21 days in SBF, but the amount of crystals clearly increases due to the increase in the areas of the features in the XRD and FTIR data associated with HCAp crystallinity. 
Fig. (10) compares the bioactivity of glass ICSW9 against 45S5 Bioglass ${ }^{\circ}$ from FTIR spectra taken on glass powders of identical particle sizes exposed to the same SBF conditions. It can clearly be seen that after 1 day in SBF the apatite formed on the ICSW9 glass is highly crystalline with intense, narrow, split peaks in the $550 \mathrm{~cm}^{-1}$ region, whereas the phosphate peak can hardly be resolved from the background in 45S5. This unequivocally shows the glasses studied here show superior bioactivity and potential as hard tissue remineralising agents compared to 45S5 Bioglass ${ }^{\circledR}$

The increased apatite formation could be a result of phase morphology. Pyrex is comprised of sodium borate rich drops in a silica rich matrix. The drops at the glass surface degrade when exposed to corrosive media, however those in the bulk are not affected. Vycor® is another phase separated borosilicate glass. However the borate phase is interconnected and the glass can be etched to form a porous structure. The high phosphate content glasses presented in this study which show increased apatite deposition may exhibit an interconnected orthophosphate morphology resulting in continuous phosphate leaching on exposure to SBF and enhanced apatite formation kinetics. This may be explained by a rapid increase in the surface area of glass exposed to solution in the initial stages of exposure.

\section{Conclusions}

Compositions are typically designed in weight percentages in the patent literature and also, surprisingly, in the scientific literature. This study avoids that approach as it is difficult to correlate changes in composition with changes in properties. The glasses presented here were designed on a molecular percentage basis. For example in the studies by Gorustovich et al. [25, 26], the authors substituted calcium oxide with strontium oxide on a weight percentage basis. No difference was seen in the two sets of samples in vivo. However, as strontium has a much higher relative atomic mass than calcium, replacing the weight of calcium in the glass with strontium would result in an increase in silica content. This would increase the network connectivity (NC [5, 6]) of the glass, slow dissolution and reduce bioactivity. The beneficial properties of adding the strontium to the glass [27], namely speeding dissolution, decreasing osteoblast differentiation and 
function whilst decreasing osteoclasts, would be cancelled out by the increase in NC. Therefore it is no surprise no real difference was seen in the calcium bioactive glass compared to the strontium sample in the study by Gorustovich et al.

In summary, two series of glasses were studied to examine both the effect of network connectivity of the silicate phase and phosphate content on bioactivity. All glasses studied produced a hydroxyl-carbonated-apatite layer on immersion in SBF for up to 21 days. The formation of this layer occurred more rapidly as the phosphate content increased for both series. This is a clear indication that in the compositional ranges studied here, phosphate content is a more important variable than the connectivity of the silicate network or an overriding factor in a process where NC and phosphate dissolution compete. The bioactivity of soda-lime-phosphosilicate glasses can be improved significantly by designing compositions with a good understanding of glass structure.

\section{References}

[1] L. L. Hench, R. J. Splinter, W. C. Allen, and T. K. Greenlee, "Bonding mechanisms at the interface of ceramic prosthetic materials," Journal of Biomedical Materials Research, vol. 5, pp. 117-141, 1971.

[2] L. J. Litkowski, G. D. Hack, and D. C. Greenspan, "Compositions containing bioactive glass and their use in treating tooth hypersensitivity," US Patent 6338751, 2002.

[3] J. E. Barry and J. A. Trogolo, "Antibiotic toothpaste," US Patent 6123925, 2000.

[4] D. W. Cannell, S. Hashimoto, K. N. Barger, and N. V. Nguyen, "Hair relaxer compositions comprising a bioactive glass," European Patent EP1709997, 2006.

[5] M. D. O'Donnell, S. J. Watts, R. V. Law, and R. G. Hill, "Effect of $\mathrm{P}_{2} \mathrm{O}_{5}$ content in two series of soda lime phosphosilicate glasses on structure and properties Part I: NMR," Journal of Non-Crystalline Solids, vol. 354, pp. 3554-3560, 2008.

[6] M. D. O'Donnell, S. J. Watts, R. V. Law, and R. G. Hill, "Effect of $\mathrm{P}_{2} \mathrm{O}_{5}$ content in two series of soda lime phosphosilicate glasses on structure and properties Part II: Physical properties," Journal of Non-Crystalline Solids, vol. 354, pp. 3561-3566, 2008.

[7] I. Elgayar, A. E. Aliev, A. R. Boccaccini, and R. G. Hill, "Structural analysis of bioactive glasses," Journal of Non-Crystalline Solids, vol. 351, pp. 173-183, 2005. 
[8] A. Krajewski and A. Ravaglioli, "Bioceramics and biological glasses," in Integrated biomaterials science, R. Barbucci, Ed. New York: Kluwer Academic/Plenum, 2002, pp. 189-254.

[9] J. C. Knowles, "Phosphate based glasses for biomedical applications," Journal of Materials Chemistry, vol. 10, pp. 2395-2401, 2003.

[10] H. Grussaute, L. Montagne, G. Palavit, and J. L. Bernard, "Phosphate speciation in $\mathrm{Na}_{2} \mathrm{O}-\mathrm{CaO}-\mathrm{P}_{2} \mathrm{O}_{5}-\mathrm{SiO}_{2}$ and $\mathrm{Na}_{2} \mathrm{O}-\mathrm{TiO}_{2}-\mathrm{P}_{2} \mathrm{O}_{5}-\mathrm{SiO}_{2}$ glasses," Journal of NonCrystalline Solids, vol. 263, pp. 312-317, Mar 2000.

[11] T. Kokubo and H. Takadama, "How useful is SBF in predicting in vivo bone bioactivity?," Biomaterials, vol. 27, pp. 2907-2915, 2006.

[12] M. E. Fleet, X. Liu, and P. L. King, "Accommodation of the carbonate ion in apatite: An FTIR and X-ray structure study of crystals synthesized at 2-4 GPa," American Mineralogist, vol. 89, pp. 1422-1432, 2004.

[13] M. Vallet-Regí, A. M. Romero, C. V. Ragel, and R. Z. LeGeros, "XRD, SEMEDS, and FTIR studies of in vitro growth of an apatite-like layer on sol-gel glasses," Journal of Biomedical Materials Research Part A, vol. 44, pp. 416-421, 1999.

[14] B. D. Cullity, Elements of X-ray diffraction. Reading, Mass.: Addison-Wesley Pub. Co., 1956.

[15] M. Regina, T. Filgueiras, G. La Torre, and L. L. Hench, "Solution effects on the surface reactions of three bioactive glass compositions," Journal of Biomedical Materials Research, vol. 27, pp. 1485-1493, 1993.

[16] O. Peitl, E. Dutra Zanotto, and L. L. Hench, "Highly bioactive $\mathrm{P}_{2} \mathrm{O}_{5}-\mathrm{Na}_{2} \mathrm{O}-\mathrm{CaO}-$ $\mathrm{SiO}_{2}$ glass-ceramics," Journal of Non-Crystalline Solids, vol. 292, pp. 115-126, 2001.

[17] O. P. Filho, G. P. La Torre, and L. L. Hench, "Effect of crystallization on apatitelayer formation of bioactive glass 45S5," Journal of Biomedical Materials Research Part A, vol. 30, pp. 509-514, 1996.

[18] D. M. Sanders, W. B. Person, and L. L. Hench, "Quantitative Analysis of Glass Structure with the Use of Infrared Reflection Spectra," Applied Spectroscopy, vol. 28, pp. 247-255, 1974.

[19] J. Serra, P. González, S. Liste, C. Serra, S. Chiussi, B. León, M. Pérez-Amor, H. O. Ylänen, and M. Hupa, "FTIR and XPS studies of bioactive silica based glasses," Journal of Non-Crystalline Solids, vol. 332, pp. 20-27, 2003.

[20] G. Penel, G. Leroy, C. Rey, B. Sombret, J. P. Huvenne, and E. Bres, "Infrared and Raman microspectrometry study of fluor-fluor-hydroxy and hydroxy-apatite 
powders," Journal of Materials Science-Materials in Medicine, vol. 8, pp. 271276, 1997.

[21] R. V. Santos and R. N. Clayton, "The carbonate content in high-temperature apatite; an analytical method applied to apatite from the Jacupiranga alkaline complex," American Mineralogist, vol. 80, pp. 336-344, April 1995.

[22] C. Rey, B. Collins, T. Goehl, I. Dickson, and M. Glimcher, "The carbonate environment in bone mineral: A resolution-enhanced fourier transform infrared spectroscopy study," Calcified Tissue International, vol. 45, pp. 157-164, 1989.

[23] F. L. Galeener and G. Lucovsky, "Longitudinal Optical Vibrations in Glasses: $\mathrm{GeO}_{2}$ and $\mathrm{SiO}_{2}$," Physical Review Letters, vol. 37, p. 1474, 1976.

[24] P. Lange, "Evidence for disorder-induced vibrational mode coupling in thin amorphous $\mathrm{SiO}_{2}$ films," Journal of Applied Physics, vol. 66, pp. 201-204, 1989.

[25] A. Gorustovich, T. Steimetz, R. L. Cabrini, and J. M. Porto López, "Osteoconductivity of strontium-doped bioactive glass particles," Bone, vol. 41, pp. S1-S13, 2007.

[26] A. Gorustovich, T. Steimetz, and J. M. Porto López, "Microchemical characterization of bone around strontium-doped bioactive glass particles," Bone, vol. 41, pp. S1-S13, 2007.

[27] R. G. Hill, Y. Fredholm, M. D. O'Donnell, E. Gentleman, G. Jell, M. Ball, and M. Stevens, "Physical and biological properties of strontium-containing bioactive glasses," Biomaterials, vol. To be submitted, 2008. 


\section{Tables}

Table (1): Glass compositions used in this study with network connectivity assuming phosphate enters the silicate network (NC) and assuming phosphate forms a separate orthophosphate phase (NC').

\begin{tabular}{|c|c|c|c|c|c|c|}
\hline \multirow{2}{*}{ ID } & \multicolumn{7}{|c|}{ Mol. \% } & \multirow{2}{*}{ NC } & \multirow{2}{*}{ NC' } \\
\cline { 2 - 5 } & SiO $_{\mathbf{2}}$ & $\mathbf{N a}_{\mathbf{2}} \mathbf{O}$ & $\mathbf{C a O}$ & $\mathbf{P}_{\mathbf{2}} \mathbf{O}_{\mathbf{5}}$ & & \\
\hline \multicolumn{8}{|c|}{ Series I } \\
\hline ICSW1 & 51.06 & 26.10 & 22.84 & 0.00 & 2.08 & 2.08 \\
\hline ICSW2 & 47.84 & 26.67 & 23.33 & 2.16 & 2.00 & 2.18 \\
\hline ICSW3 & 44.47 & 27.26 & 23.85 & 4.42 & 1.92 & 2.30 \\
\hline ICSW5 & 40.96 & 27.87 & 24.39 & 6.78 & 1.83 & 2.44 \\
\hline ICSW4 & 37.28 & 28.52 & 24.95 & 9.25 & 1.75 & 2.62 \\
\hline \multicolumn{7}{|c|}{ Series II } \\
\hline ICSW6 & 48.98 & 26.67 & 23.33 & 1.02 & 2.00 & 2.08 \\
\hline ICSW7 & 47.07 & 27.19 & 23.78 & 1.95 & 1.92 & 2.08 \\
\hline ICSW8 & 43.66 & 28.12 & 24.60 & 3.62 & 1.79 & 2.08 \\
\hline ICSW10 & 40.71 & 28.91 & 25.31 & 5.07 & 1.67 & 2.08 \\
\hline ICSW9 & 38.14 & 29.62 & 25.91 & 6.33 & 1.56 & 2.08 \\
\hline
\end{tabular}

Table (2): Time for crystalline apatite formation observed by splitting of the FTIR P-O bending mode at around $550 \mathrm{~cm}^{-1}$ (sample ICSW4 partially crystalline).

\begin{tabular}{|c|c|c|}
\hline ID & Mol. \% $\mathbf{P}_{\mathbf{2}} \mathbf{O}_{\mathbf{5}}$ & Time \\
\hline \multicolumn{3}{|c|}{ Series I } \\
\hline ICSW1 & 0.00 & 1 week \\
\hline ICSW2 & 2.16 & 2 days \\
\hline ICSW3 & 4.42 & 16 hours \\
\hline ICSW5 & 6.78 & 16 hours \\
\hline ICSW4 & 9.25 & 1 day \\
\hline \multicolumn{3}{|c|}{ Series II } \\
\hline ICSW6 & 1.02 & 2 days \\
\hline ICSW7 & 1.95 & 2 days \\
\hline ICSW8 & 3.62 & 16 hours \\
\hline ICSW10 & 5.07 & 16 hours \\
\hline ICSW9 & 6.33 & 16 hours \\
\hline
\end{tabular}




\section{Figures}

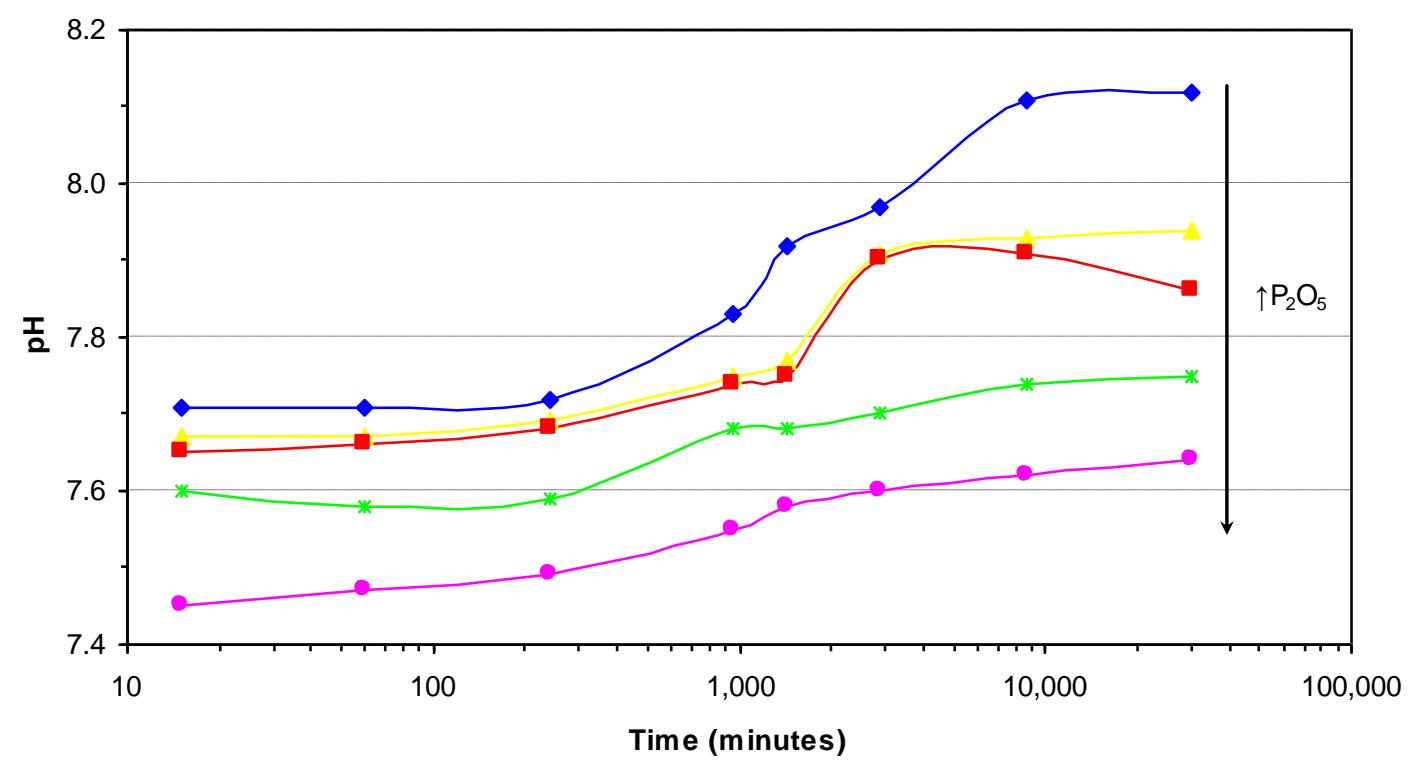

$\multimap$ ICSW1 $\triangle$ ICSW2 $\rightarrow$ ICSW3 $\rightarrow$ ICSW5 $\bullet$ ICSW4

Fig. (1): $\mathrm{pH}$ variation of SBF for series I glasses.

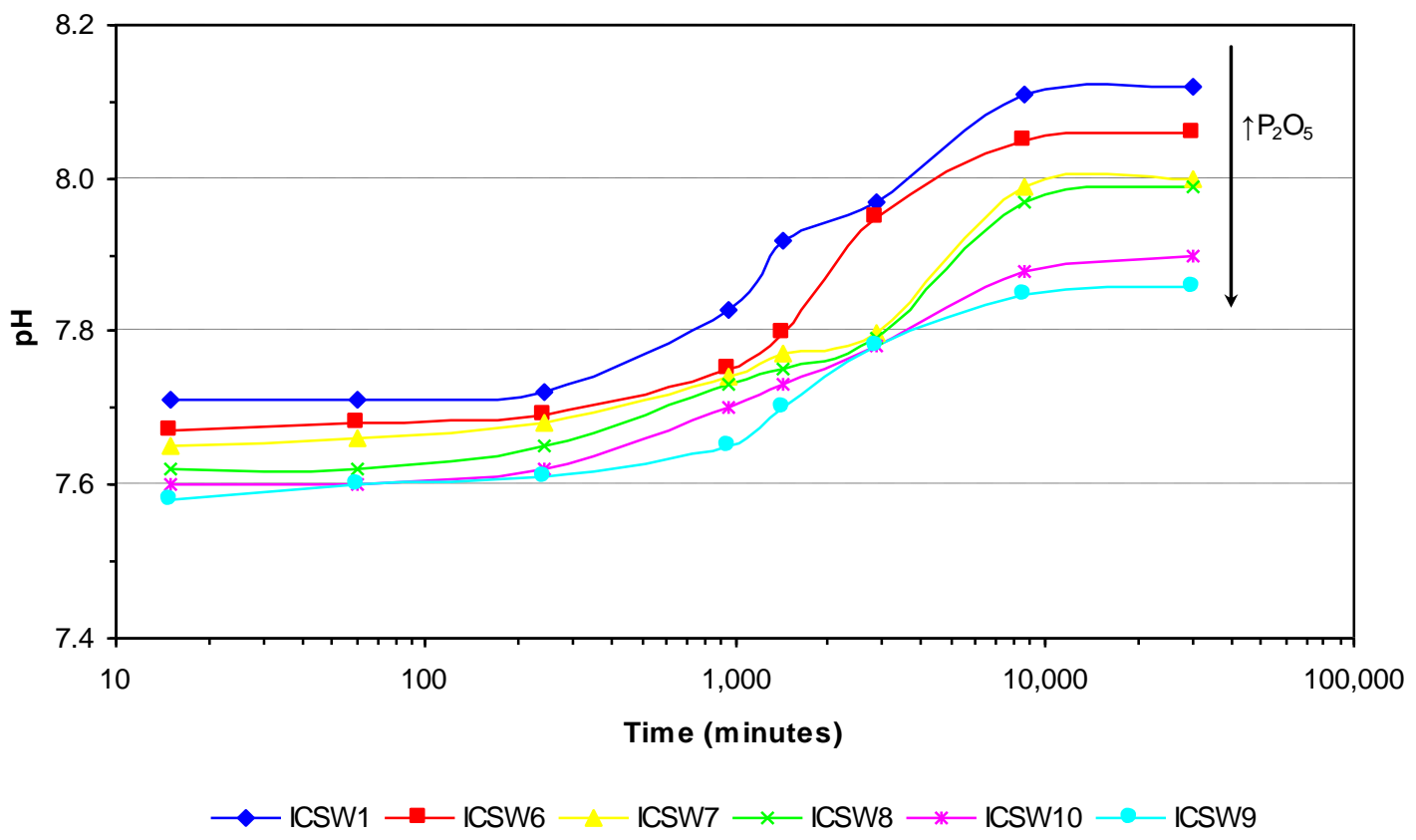

Fig. (2): $\mathrm{pH}$ variation of SBF for series II glasses. 


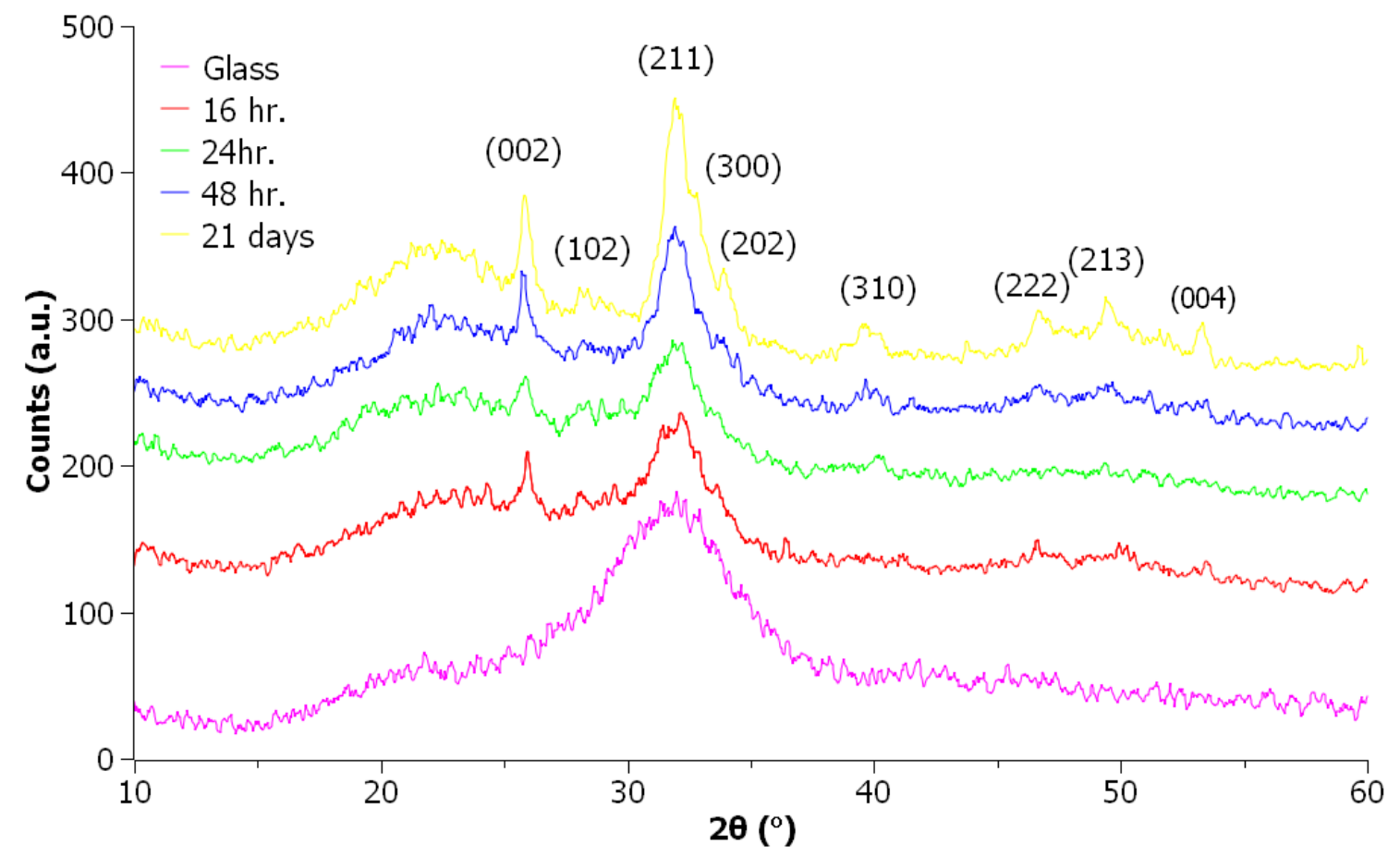

Fig. (3): XRD traces for series I glass ICSW03 (4.42 mol. \% $\mathrm{P}_{2} \mathrm{O}_{5}$ ) with time of immersion in SBF with the main Bragg peaks labelled.

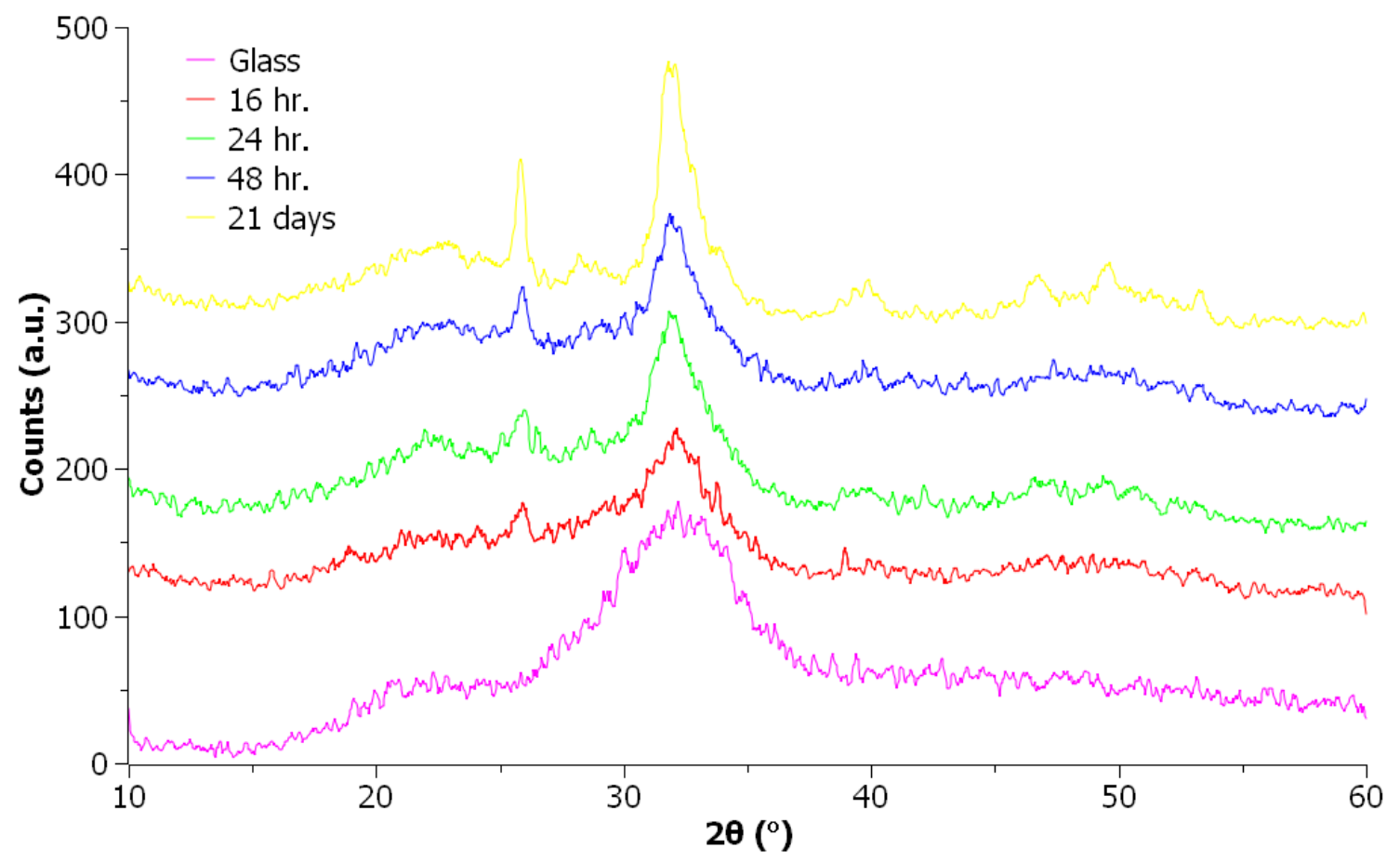

Fig. (4): XRD traces for series II glass ICSW09 (6.33 mol. \% $\mathrm{P}_{2} \mathrm{O}_{5}$ ) with time of immersion in SBF. 


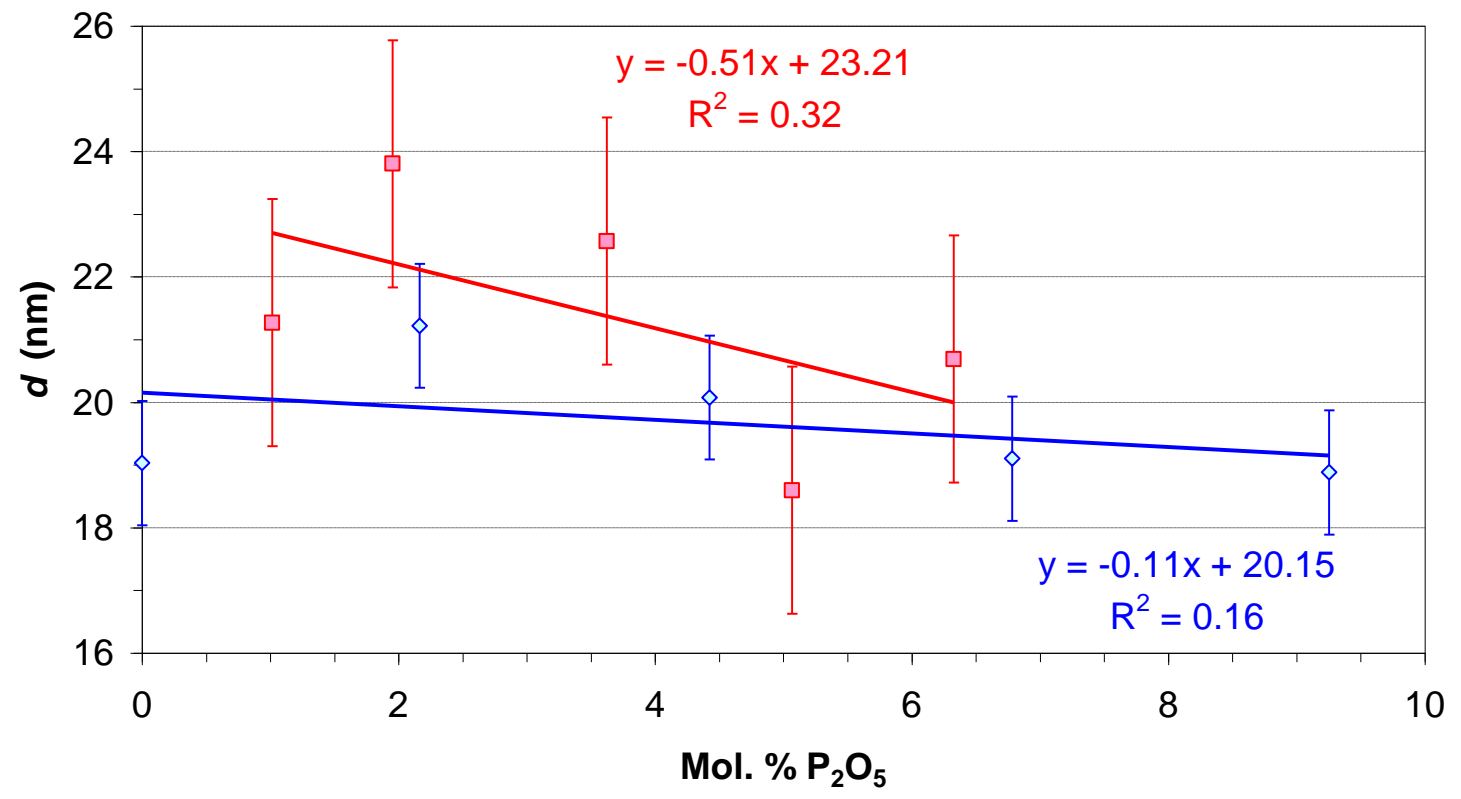

$\diamond$ Series I $\square$ Series II

Fig. (5): Crystallite size analysis from 002 Bragg peak for both series of glasses. 


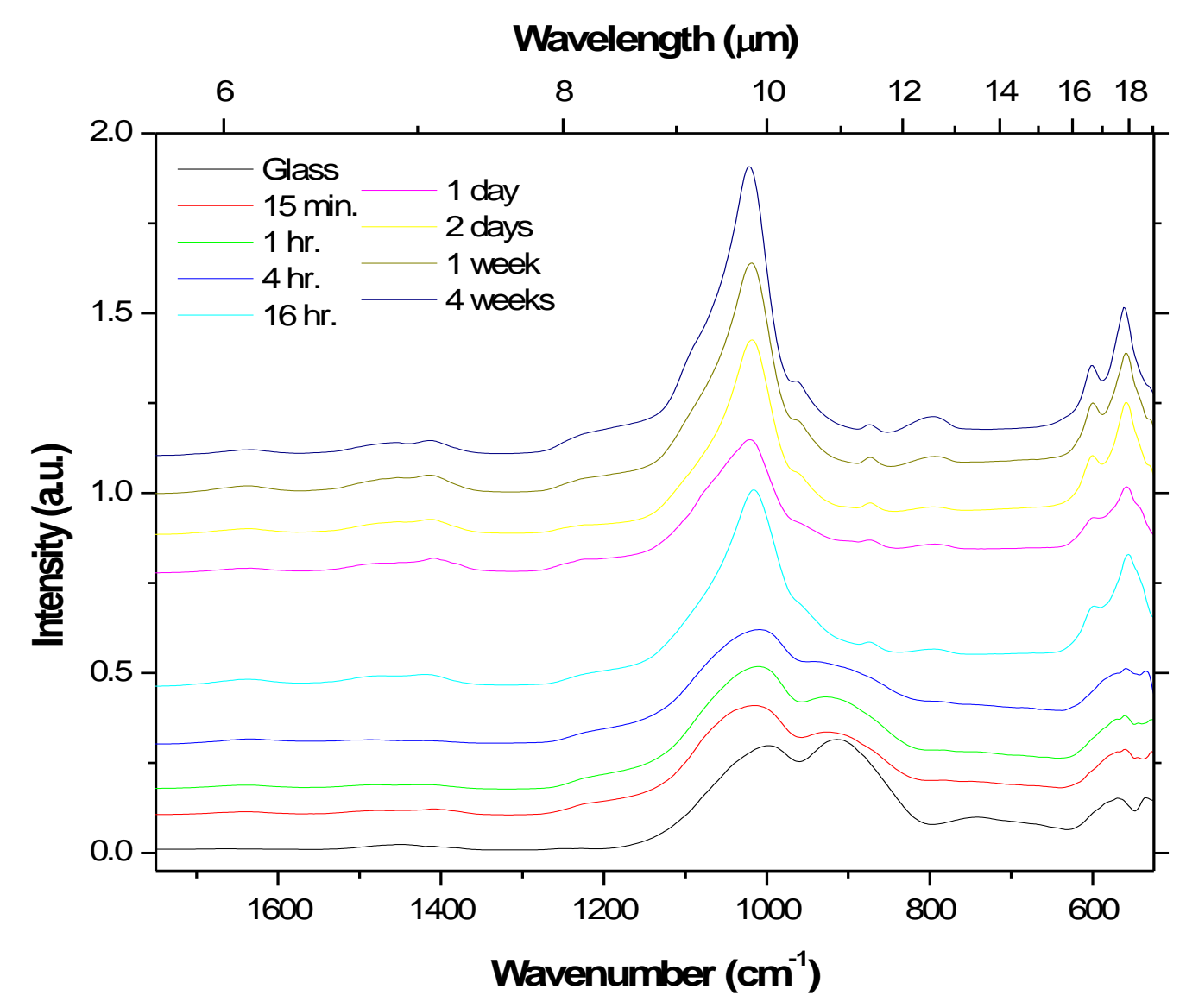

Fig. (6): FTIR spectra of series I glass ICSW05 (6.79 mol. \% $\left.\mathrm{P}_{2} \mathrm{O}_{5}\right)$ with time of immersion in SBF. 


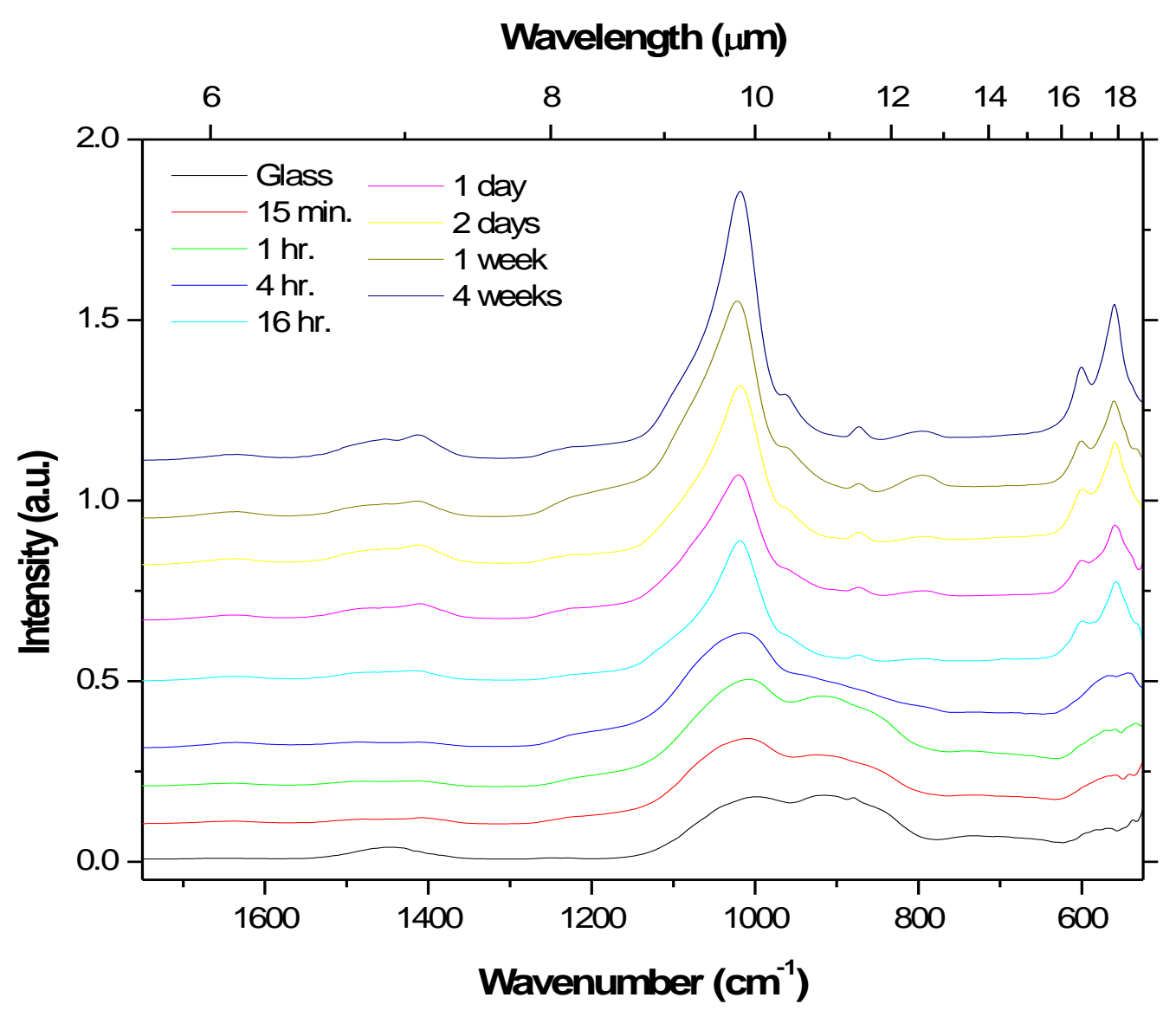

(a) 


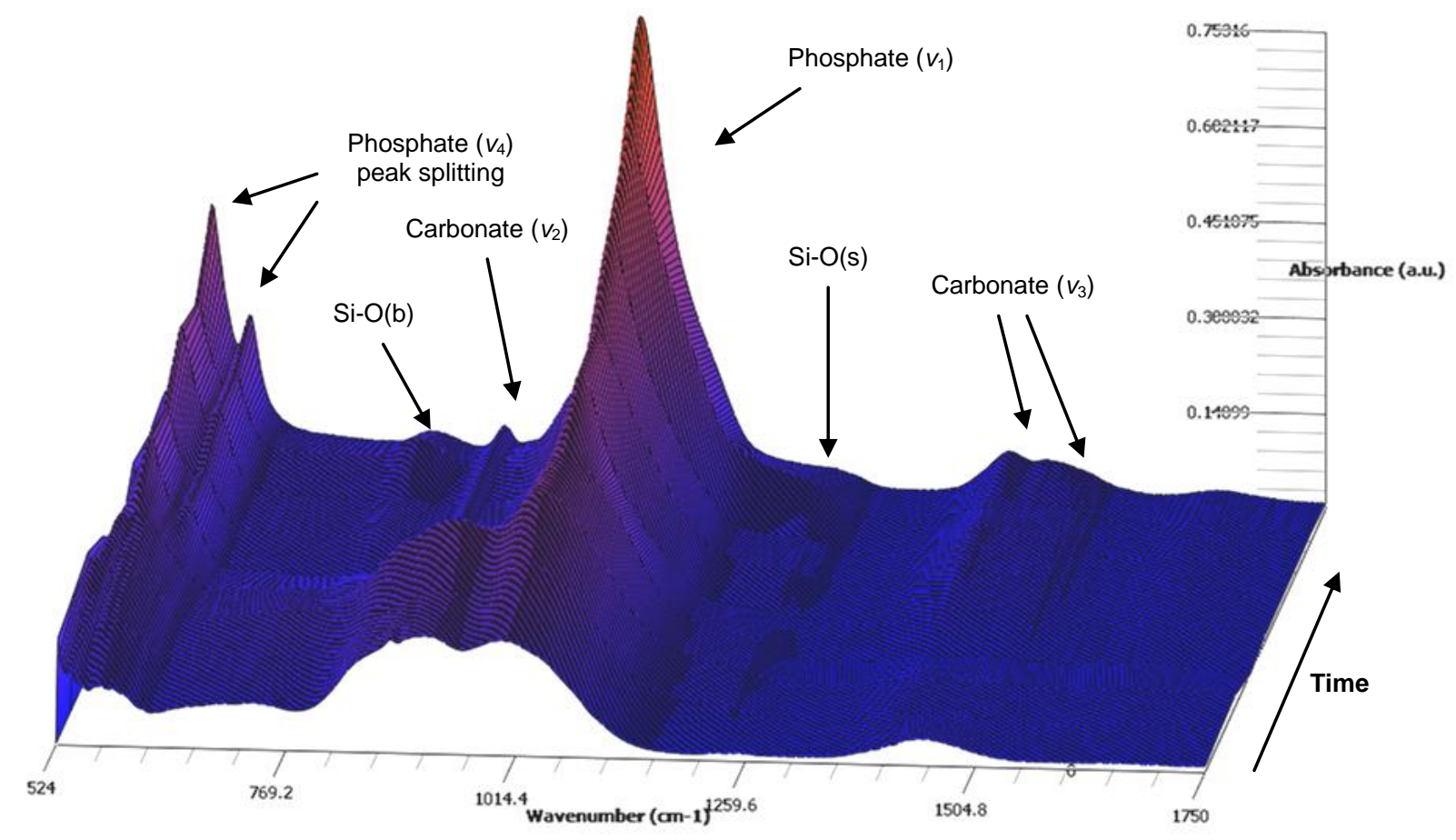

(b)

Fig. (7): (a) FTIR spectra of series II glass ICSW10 (5.07 mol. \% $\mathrm{P}_{2} \mathrm{O}_{5}$ ) with time of immersion in $\mathrm{SBF}$ and (b) 3D contour plot (time axis not linear). 


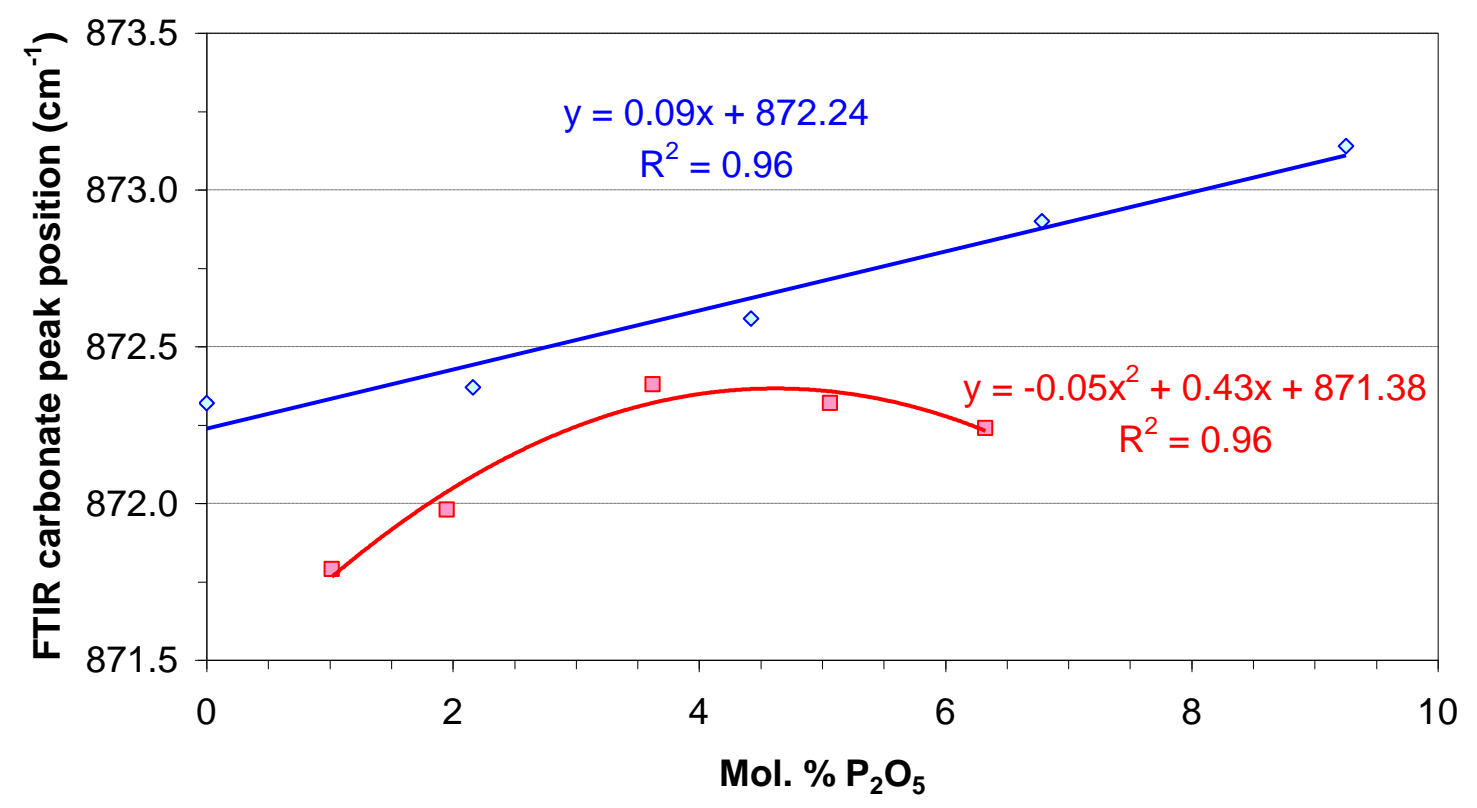

$\diamond$ Series I $\square$ Series II

Fig. (8): Dependence of carbonate peak position from FTIR on parent glass phosphate content after 21 days in SBF.

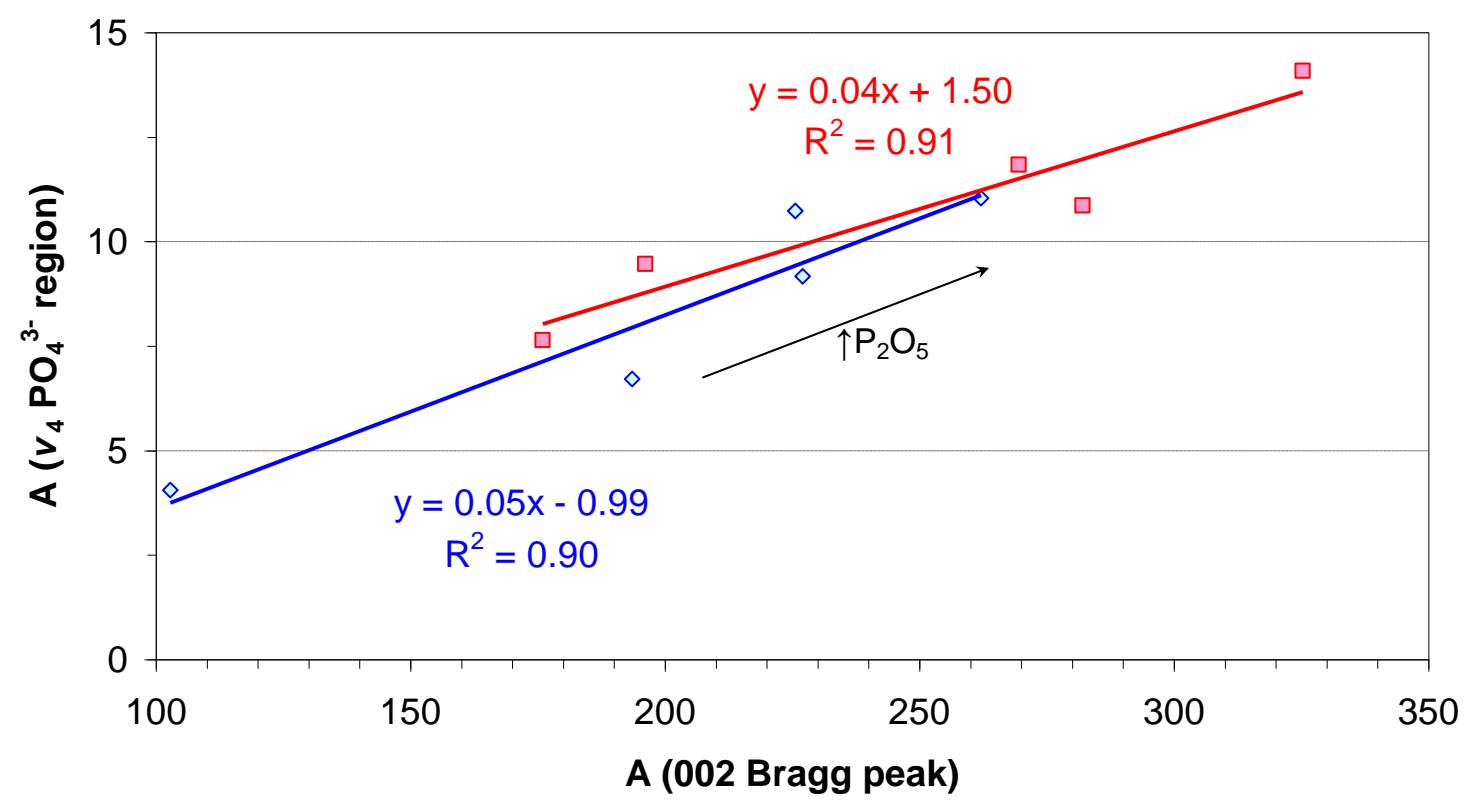

$\diamond$ Series I $\square$ Series II

Fig. (9): Area of $v_{4}$ phosphate FTIR region plotted against (002) Bragg peak area from XRD after 21 days in SBF. 


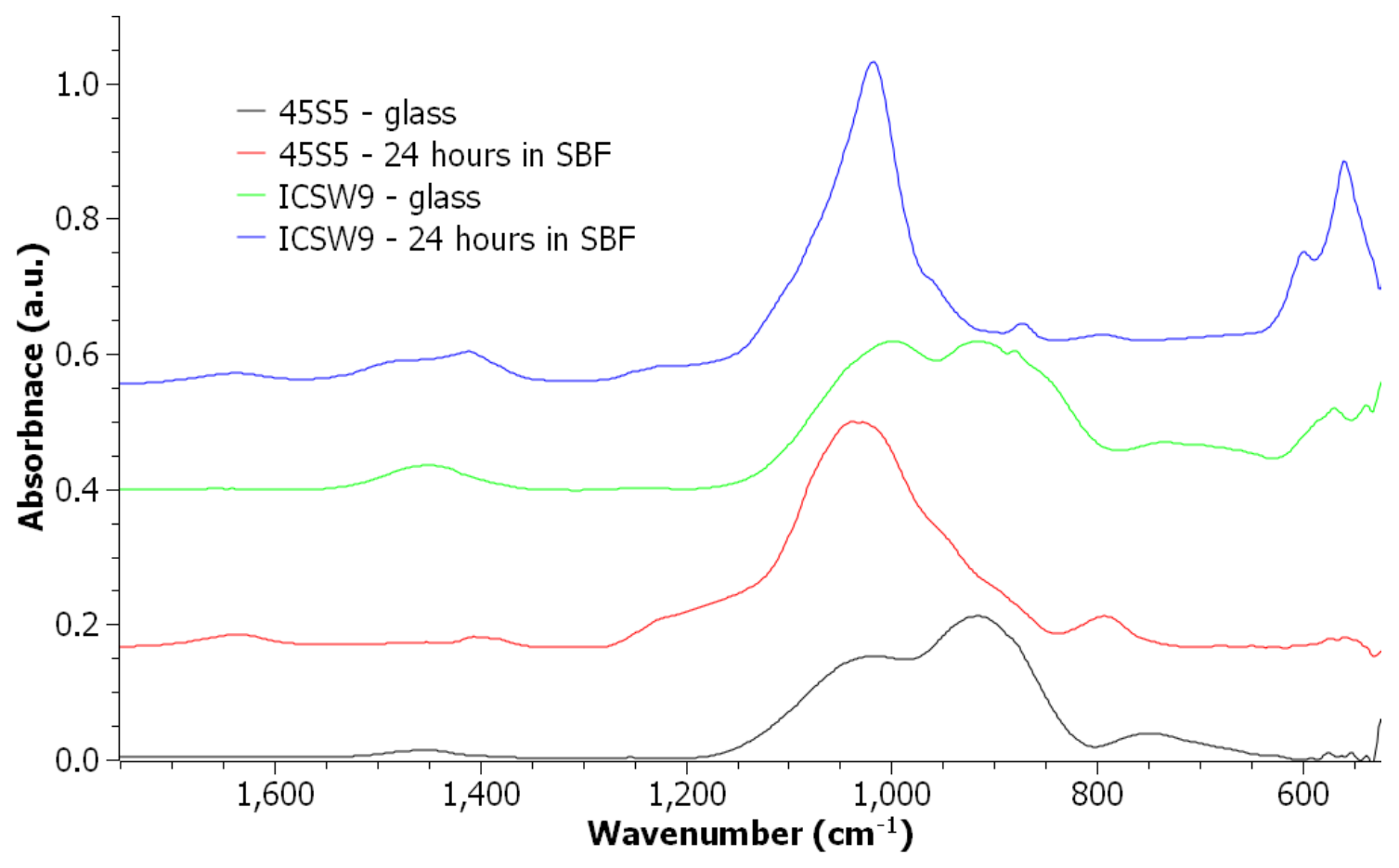

Fig. (10): Comparison of ICSW9 and 45S5 Bioglass® by FTIR after 24 hours in SBF. 